\title{
¿PIRATAS VÁNDALOS EN EL CANTÁBRICO? ACERCA DE UNA SUPUESTA INCURSIÓN MARÍTIMA DE UNOS WANDALI EN LA NOVEMPOPULANIA (PRIMERA MITAD DEL SIGLO V)*
}

\author{
VANDAL PIRATES IN THE CANTABRIAN SEA? \\ ABOUT AN ALLEGED MARITIME RAID FROM SOME WANDALI \\ IN NOVEMPOPULANIA (FIRST HALF OF THE 5TH CENTURY)
}

\author{
Jokin LANZ** \\ Universidad del País Vasco (UPV/EHU)
}

\begin{abstract}
RESUMEN. El presente estudio realiza un acercamiento histórico de la mención a un ataque perpetrado en Novempopulania por una flota vándala tras haber remontado el río Adour en algún momento de la primera mitad del s. V. El pasaje que recoge el acontecimiento ha pasado casi desapercibido entre los historiadores debido a que se enmarca en una obra apócrifa redactada en época medieval, la hagiografía de Severo martyr in Novempopulania o in Vasconia, una leyenda de fundación monástica que gira en torno al religioso Severo y los orígenes del monasterio de Saint-Sever. Mediante el análisis de la época donde se circunscribe la citada incursión pirática, procederemos a realizar una interpretación de los hechos.
\end{abstract}

PALABRAS CLAVE: Antigüedad Tardía, Novempopulania, vándalos, piratas, hagiografía.

ABSTRACT. The following study offers a historical analysis of the raid suffered in Novempopulania by a Vandal fleet after having sailed up the Adour river at some stage during the first half of the $5^{\text {th }}$ century. The passage narrates the events that have been mostly unnoticed among historians due to the fact that it is included in an apocryphal literary work written in the medieval period, the hagiography of Severus martyr in Novempopulania or in Vasconia, a founding monastic legend about Severus and Saint-Sever monastery's origins. Through a historical approach where the aforementioned maritime incursion occurred, we will proceed to analyse the account of the events.

KEYWORDS: Late Antiquity, Novempopulania, Vandals, pirates, hagiography.

* Este trabajo se ha realizado en el periodo de contratación como doctor reciente hasta la integración en programas de formación postdoctoral en la UPV/EHU (Dokberri 2017) en el área de Historia Antigua del Departamento de Estudios Clásicos.

** Correspondencia a / Correspondence to: Jokin Lanz, calle Cubo 14, 3. dcha, C.P. 01001, Vitoria-Gasteiz (Álava) - jokin.lanz@ehu.eus - https:// orcid.org/0000-0002-4026-5543.

Cómo citar / How to cite: Lanz, Jokin (2020), "¿Piratas vándalos en el Cantábrico? Acerca de una supuesta incursión marítima de unos Wandali en la Novempopulania (primera mitad del siglo v)", Veleia, 37, 197-210. (https://doi.org/10.1387/veleia.20709).

Recibido: 26 marzo 2019; aceptado: 5 noviembre 2019.

ISSN 0213-2095 - elSSN 2444-3565 / (C) 2020 UPV/EHU

(c) Esta obra está bajo una licencia

Creative Commons Atribución 4.0 Internacional 


\section{INTRODUCCIÓN}

Aprovechando que el río Rin estaba helado, el último día del año $406^{1}$, grupos de vándalos, suevos y alanos, junto con otros pueblos, cruzaron el limes internándose en las Galias. La presencia de estos bárbaros con las consecuentes razias que realizaban contribuyó a la desestabilización de la autoridad imperial en occidente favoreciendo que prosperasen numerosas usurpaciones en el ejército romano, descuidando las fronteras de forma alarmante. En este contexto, numerosos grupos piratas de origen bárbaro se valieron para realizar sus razias en territorio imperial e, incluso, en los reinos bárbaros recién constituidos en suelo romano.

En esta ocasión nos disponemos a analizar una incursión marítima recogida en un pasaje de una obra anónima que, por su carácter hagiográfico y redacción tardía, ha pasado casi desapercibida para los historiadores: el De Sancto Severo martyr in Novempopulania o in Vasconia, una leyenda de fundación monástica que gira en torno al religioso Severo mártir en Novempopulania ${ }^{2}$. Las diferentes versiones de esta obra, escritas en el siglo $\mathrm{XI}^{3}$, son la única fuente que tenemos respecto a una escaramuza entre unos vándalos llegados por mar y una guarnición local en una fecha incierta durante la primera mitad del siglo v cerca del actual Saint-Sever (Landes). Como todos los textos hagiográficos, el autor toma como eje de la obra los milagros y labores de evangelización que supuestamente realizó el santo, sin que llegue a concretar demasiado los detalles de los acontecimientos paralelos que afectaron al protagonista. Según el hagiógrafo, Severo era rey de un pueblo bárbaro de origen escita en época del emperador Juliano (360-363). Tras convertirse al catolicismo, el futuro mártir dejó el trono y tras vivir varias vicisitudes, terminó ejerciendo su misión evangelizadora en Novempopulania - territorio al que anacrónicamente llama Vasconia - llegando al castro de Palaestrion ${ }^{4}$, un antiguo fuerte de origen romano situado en el interior -erat enim interioribus partibus Vasconiae ex antiqua Romanorum constitutione famosissimum oppidum - y que albergaba una guarnición al mando de un rey — rex - llamado Adrianus, que se encontraba enfermo. Severus, que contaba con la ayuda de Cristo, realizó un exorcismo haciendo que huyeran los demonios que acosaban a Adrianus, consiguiendo con ello que el rex se curara y se convirtiera al catolicismo, ejemplo que siguieron los miembros del destacamento que comandaba y los habitantes de los alrededores. Poco después, unos vándalos con sus naves remontaron el río - Alpheanus fluvium - penetrando en el territorio -intra Vasconicas partes penetravit - hasta el castro de Palestrion. Gracias a los rezos de Severo, la providencia divina actuó en favor de los soldados acantonados desatando una inundación que desbarató parte de la flota vándala, pero no se pudo evitar el ataque y, aunque los incursores pudieron ser rechazados, el uno de noviembre el religioso murió decapitado en el transcurso de la lucha convirtiéndose en mártir. Según la tradición, Severo realizó un miracula post mor-

1 Todas las fechas señaladas a lo largo del artículo son d.C. a no ser que se indique lo contrario.

2 El término denomina la provincia romana creada a partir de las reformas de Diocleciano a finales del siglo III y ubicada en el suroeste galo, que reunía a doce civitates abarcando, aproximadamente, los territorios que se encuentran entre el río Garona y los Pirineos (Lanz 2016, 545).

3 Se han conservado tres versiones de la anónima vita del santo Severo de Novempopulania. Todas ellas contienen un marcado carácter apócrifo y en ocasio- nes muestran contradicciones entre sí haciendo realmente difícil su interpretación histórica. La redacción de las primeras dos versiones se llevó a cabo en pleno siglo XI, mientras que la tercera fue escrita algunos años antes. Entre estas, son la primera - prima - y la tercera - tertia - versiones las que recogen las referencias más abundantes en torno a la Novempopulania, ya que la $s e-$ cunda es un breve resumen de las dos anteriores escrita en verso (Baillet 2009, 55-61).

4 Identificable tal vez con el castillo de Morlanne, no lejos de la abadía de Saint-Sever (Baillet 2009, 72). 
tem caminando con la cabeza bajo el brazo hasta el lugar donde quiso ser enterrado, tumba sobre la que se fundó la abadía de Saint-Sever ${ }^{5}$.

Generalmente, el objetivo principal de los textos historiográficos dista mucho del de ofrecer una visión histórica de los hechos. En el caso de la Vita de Severo, más allá de la fuerte influencia que recibe de otras vitae anteriores, su redacción persigue propósitos vinculados a defender la legitimidad de las estructuras políticas y eclesiásticas propias del Ducado de Gascuña en el contexto de su integración dentro del Ducado de Aquitania en la segunda mitad del siglo xI. De hecho, el encuentro con los piratas nos recuerda la vez en que, hacia el 981-982, el duque gascón Guillermo Sanchó derrotó y expulsó a unos vikingos que habían penetrado hacia el interior por el río Adour, éxito que fue posible, según la tradición, gracias a la intervención divina de san Severo en el campo de batalla. Por todo ello, la Vita ha sido desechada como fuente histórica para la época Antigua por gran parte de la comunidad científica (Courtois 1955, 44-45; Baillet 2009, 61-63 y 93; Cabanot \& Pon 2009, 53). Sin embargo, manteniendo las distancias, opinamos que el relato puede conservar una base real ligada a la tediosa inseguridad vivida por las comunidades del litoral cantábrico durante los años de desintegración y posterior caída del Imperio Romano de Occidente. Para ello, estimamos oportuno destacar algunas precisiones en torno a la piratería en la Antigüedad Tardía.

\section{La Piratería En la ANTigüedad Tardía}

Los autores griegos y latinos utilizan términos similares para referirse a la piratería. Estos últimos manejan habitualmente el vocablo praedo - a veces aparece como maritimus praedo-, que deriva de praeda ('botín, saqueo'), y pirata, que viene claramente de la voz griega peirates. En ocasiones también se recurre a la genérica expresión de latro para referirse al individuo y latrocinium para la acción que ejecuta, mientras que en griego podemos ver el término leistes que contiene un significado similar (De Souza 2002, 12-13; Alvarez Jiménez 2010, 15-16). Sin embargo, la piratería en la Antigüedad ha recibido escasa atención por parte de los investigadores, situación que se agrava para el caso del periodo tardoantiguo ${ }^{6}$. Una de las razones objetivas descansa en el humilde carácter de las fuentes, mayormente literarias, al que tiene que enfrentarse el historiador. Gran parte de las veces, la mención escrita a este tipo de acto criminal es meramente circunstancial y los pasajes donde se recogen las acciones piráticas son escuetos y se encuentran diseminados en fuentes de diversa índole, como trabajos historiográficos, poemas, novelas, correspondencia o hagiografías. A ello debemos sumarle la percepción negativa de todo lo relacionado con la mar en la mentalidad romana tradicional. Según esta, el mar estaba rodeado por un halo de misterio donde la posibilidad de naufragio y la muerte estaban muy presentes. Asimismo, tanto en la religión griega como en la romana no se concebía peor destino que la muerte en alta mar, ya que la ausencia de una sepultura digna impedía a los fallecidos descansar en paz sentenciándolos a permanecer en una especie de limbo. Más tarde esta visión negativa fue heredada por el cristianismo, adecuándola a su credo (Lindenlauf 2003, 423; Álvarez Jiménez 2010, 2-9).

5 Sever. Novemp. Prima 20-27; Tertia 27-29.

\footnotetext{
6 Entre los trabajos más sobresalientes que tratan la piratería tardoantigua: Haywood 1991, De Souza 2002, y las obras de Álvarez Jiménez, sobre todo las publicadas en 2010 y 2016.
} 
A pesar de las connotaciones negativas que albergaba, la navegación era necesaria y su vinculación con la piratería era prácticamente indisoluble e, incluso, bien vista en el seno de la gran mayoría de las comunidades costeras de la Antigüedad. En cambio, con la expansión romana y la aplicación del ius gentium en las relaciones internacionales, el latrocinium marítimo comenzó a tratarse por las autoridades romanas como un mal a combatir. Aun admitiendo su utilidad como proveedora de esclavos ${ }^{7}$, la piratería representaba un grave peligro para la estabilidad del poder romano (Álvarez Jiménez 2010, 13). Empero, al igual que sucedía con los bandidos de tierra firme, los piratas eran etiquetados de criminales y no podían ser tratados como un enemigo justo ${ }^{8}$. De esta forma, a los cautivos realizados por los praedes, a diferencia de aquellos tomados por los enemigos de Roma, no se les aplicaba el postliminium cuando recobraban su libertad, ya que ello implicaría un reconocimiento jurídico-político de los praedones maritimi, algo inconcebible para la potencia itálica ${ }^{9}$. Aun así, la piratería y las acciones que se aplicaban para combatirla contribuían a legitimar el discurso ideológico romano y servía, a veces, como elemento de desprestigio y deslegitimación de aquellos enemigos del estado, calificándolos de piratas o de colaborar con estos (De Souza 2002, 220; Álvarez Jiménez 2010, 33).

En las fuentes se puede percibir, en ocasiones con dificultad, la diferencia entre la piratería generada dentro de la sociedad romana y aquella ejercida por diversas comunidades bárbaras que habitaban más allá de las fronteras. Ambas formas, aludidas en los mismos términos, estuvieron presentes durante toda la Antigüedad y jamás fueron erradicadas. La piratería interna o criminal pasa casi totalmente desapercibida en los textos grecorromanos. En cambio, los pasajes donde se recogen diversos ataques por mar realizados por grupos bárbaros, aunque escasos, transmiten la existencia de una amenaza que sobrepasa lo anecdótico, especialmente en los momentos en los que languidecía el poderío militar romano (Álvarez Jiménez 2005, 116 y 121, nota 22). Sin embargo, debido a que estos incursores marítimos apenas llaman la atención de los autores clásicos, desconocemos muchos aspectos del modo en que se organizaban y llevaban a cabo sus operaciones. Se piensa que los piratas emprenderían sus acciones de saqueo en periodo estival y desde bases seguras que, provisionales o no, bien podrían situarse lejos de sus hogares y cerca de los objetivos. En su proceder destaca la sorpresa como factor fundamental ${ }^{10}$, seguido del saqueo y la toma de cautivos haciendo uso de armamento ligero para huir rápidamente del lugar antes de que se personase ninguna fuerza que les hiciera frente. Con excepción de los vándalos asentados en el norte de África, excelentes marinos y dueños de una poderosa flota de guerra a partir del 439 (Álvarez Jiménez 2016, 113), podría decirse que los piratas eran conscientes de su modesto potencial bélico ante tropas disciplinadas y por ello evitaban el encuentro armado siempre que podían.

El carácter depredador y fugaz de los ataques de los praedones maritimi nos hace suponer que los captivi o el conjunto de personas capturadas se superpondrían a los rehenes u obsides obtenidos mediante tratados (Álvarez Pérez-Sostoa 2009, 149; Huntzinger 2009, 225-227; Gueye 2013, 31-35).

7 Estr. 14.5.2.

8 Rampazzo 2005; Álvarez Jiménez 2010, 19. La única definición de los piratas de la Antigüedad, aunque redactada en época tardía, nos la proporciona Isidoro de Sevilla quien los identifica como "salteadores marinos» - Piratae sunt praedones maritimi_- (Isid. Etym. 10.220).

\footnotetext{
9 El ciudadano romano que caía prisionero, durante el periodo en que permanecía en esta situación, perdía su posición social y jurídica dentro de la comunidad romana y una vez liberado de su cautiverio, el postliminium organizaba su regreso para que le fueran restaurados su estatus y posición social anterior a su apresamiento (Connolly 2006, 116; Huntzinger 2009, 27-53, 77-78 y 120-36).

10 Amm. 28.2.12; Sid. Apol. Epist. 8.6.13-16.
} 
En la Antigüedad, el destino de los prisioneros de guerra variaba según su status social, siendo lo más habitual que se les redujese a la esclavitud para venderlos en el mercado, una práctica reconocida por el derecho de guerra. Como parte indispensable del botín, su venta como esclavos constituía una atractiva fuente de ingresos y estos beneficios podían verse incrementados con la venta de objetos y animales robados durante los saqueos ${ }^{11}$. En el mejor de los casos, los allegados de los prisioneros más pudientes lograban pagar un rescate por su liberación ${ }^{12}$, pero no era extraño que adquirieran la condición de rehenes ${ }^{13}$. Asimismo, en el oriente tardoantiguo algunos prisioneros de guerra pasaban a servir en el ejército, indubitablemente hombres en edad de combatiir ${ }^{14}$. Fuera cual fuera su destino, los prisioneros poseían una fuerte carga ideológica, ya que eran explotados tanto política como simbólicamente por aquellos que los capturaban. Su presencia administraba cierto optimismo en la moral de la comunidad de los secuestradores mientras que resultaba un golpe psicológico nada desdeńable para los allegados de las víctimas, acrecentando el poder del rey o jefe vencedor ante sus súbditos y sus enemigos (Allen 2006, 96-125; Álvarez Pérez-Sostoa 2009, 333366 y 367-386; Huntzinger 2009, 317-322). Las fuentes apenas hablan del trato que recibían las personas capturadas, pero los escasos comentarios que reflejan extrañeza o alivio ante las condiciones dignas en las que son asistidas algunas de ellas, generalmente las de alto rango, tal vez sugiera que habitualmente los captivi fueran injuriados y torturados, seguramente en el mismo momento de su captura y a la hora de ser interrogados (Bielman \& Duckrey 2003, 86; Lenski 2011a, 194; Lanz 2015, 104). No obstante, no podemos olvidar que los malos tratos no alcanzarían un grado extremo, ya que la mayoría de los destinos que aguardaban a los captivi requerían que estos estuviesen en unas condiciones mínimamente razonables.

El enorme esfuerzo realizado por Octavio Augusto en la instauración de la Pax Romana conllevó a que las acciones piráticas en las aguas que bañaban al imperio romano se redujesen a sus cotas más bajas al menos durante los primeros dos siglos de nuestra era, aunque jamás se consiguió erradicarlas del todo ${ }^{15}$. Las migraciones bárbaras acaecidas a comienzos del siglo $\mathrm{v}$ y las continuas usurpaciones que se sucedieron en el seno del ejército romano de occidente, tra-

11 Duckrey 1968; Herrman-Otto 2002, 1-14; Huntzinger 2009, 105; Lenski 2011a, 187-188. Así, durante el siglo v las fuentes recogen que los Mauri en sus razias en el entorno del limes africano tomaban prisioneros para ganar dinero con su venta (véase referencias en: Huntzinger 2009, 214-217), los vándalos esclavizaban de modo sistemático a los prisioneros que realizaban en sus acciones piráticas (Pos. Cal. Vit. Aug. 28; Prisc. Frag. 39.1.19-22; Vict. Vit. Hist., 1.25), los rugos vendían en el mercado a los habitantes de la antigua provincia romana del Nórico que capturaban (Eug. vit. Severin. 8.2 y 9.1), y los hunos actuaban de manera similar (referencias en: Huntzinger 2009, 115-116), al igual que los visigodos antes de asentarse en Aquitania (Claud. Get. 616-620; Zos. 5.5.6). En cambio, se sabe que los persas tendían a pagar a los sarracenos que luchaban a su servicio mediante la cesión de los prisioneros realizados en las acciones militares, cautivos que acababan vendiéndose en los mercados de Persia y de la India (Lenski 2011b, 249).
12 La figura del cautivus víctima de extorsión bajo amenaza de tortura o muerte está bien atestiguada en las acciones de hunos, visigodos y vándalos a lo largo del siglo $\mathrm{v}$, pues en cuanto que son comunidades móviles, la coerción y extorsión eran algunas de las vías más fáciles y cómodas de hacer botín (Huntzinger 2009, 196-208; Lenski 2011b, 237).

13 Para el caso del entorno aquitano-vascón: Lanz 2017, 197-198.

${ }^{14}$ Lee 2007, 82 y 137; Lenski 2014, 239-240. Comunidades en masa, como la de algunos germanos llevados por Probo en el siglo III desde la ribera del Rin a territorio imperial (SHA, Probus, 18.2.3), o la de los vándalos tras ser conquistado su reino de África, que fueron deportados a otras tierras dentro del Imperio Bizantino para que sirviesen en el ejército como tropas de caballería (Conant 2012, 60).

${ }^{15} \mathrm{Al}$ igual que el bandidismo, la piratería nunca fue erradicada (Shaw 1984, 14; Braund 1993, 199 y 206; De Souza 2002, 197 y 199; Álvarez Jiménez 2010, $24-25$ y 59$)$. 
jeron el derrumbe y abandono de las defensas norteñas y el repliegue de las tropas acantonadas en Britania en el 410, abandonando la isla a su suerte. Así, aprovechando el progresivo desmoronamiento del Imperio Occidental y la inestabilidad producida por las migraciones bárbaras, durante las siguientes décadas la piratería vivió una época dorada que solamente comenzó a languidecer tras el definitivo asentamiento de los recién llegados y la conquista bizantina del norte africano con la consiguiente desaparición del reino vándalo en la primera mitad del siglo vi (Álvarez Jiménez 2016, 305).

A riesgo de excedernos demasiado, entendemos que este marco teórico es suficiente para poder contextualizar el supuesto ataque pirata vándalo recogido en la obra hagiográfica entorno a san Severo de Novempopulania y proceder así a su análisis histórico.

\section{ANÁLISIS}

Tal como hemos señalado al inicio, a partir de la ruptura del limes a comienzos del siglo v, las fuentes literarias constatan la presencia de grupos de piratas en el mar Cantábrico ${ }^{16}$. El obispo Orencio de Auch, contemporáneo a los hechos, señala en un tono apocalíptico que el territorio galo quedó devastado, resaltando que ni siquiera las regiones inaccesibles desde el mar se libraron de la destrucción y el saqueo ${ }^{17}$, una referencia directa a la intensa actividad pirática que sufrió la zona. El religioso Jerónimo de Estridón también se lamenta de los desastres causados por las migraciones bárbaras que, según él, lo devastaron — vastarunt - todo desde los Alpes hasta los Pirineos, desde el río Rin hasta el Océano, saqueando varias ciudades importantes y arrasando las provincias de Aquitania, Novempopulania, Lugdunense y Narbonense ${ }^{18}$. Debemos tratar estos testimonios con suma cautela debido al enorme peso religioso y pesimista que los caracterizan, pero no cabe duda de que fueron escritos en tiempos convulsos que supusieron el inicio de un nuevo auge de la piratería, especialmente después de que en el 410 el emperador Honorio decidiera retirar las tropas de Britania conminando a sus habitantes a que afrontasen la defensa por sus propios medios ${ }^{19}$, decisión que señala el abandono de gran parte del limes marítimo del norte —el litus Saxonicumexponiendo los territorios romanos que miraban al Atlántico a las constantes correrías de los piratas bárbaros. Empero, al comienzo de la centuria, dicha amenaza pirática, aunque intensa, sería hasta cierto punto marginal en comparación con los ataques por tierra, recibiendo en consecuencia escasa atención por parte de las fuentes escritas (Álvarez Jiménez 2010, 603). Al parecer el tractus Armoricani et Nervicani que protegía el noroeste galo, aunque debilitado, sobrevivió durante algún tiempo y, según varios investigadores ${ }^{20}$, pudo verse reforzado con el foedus del 418 con el que se instalaron los visigodos como pueblo federado en una franja territorial que, siguiendo por el norte del Garona, iba desde Toulouse hasta Burdeos ${ }^{21}$. Más tarde, las acuciantes necesidades militares del

\footnotetext{
16 Con anterioridad, en la segunda mitad del siglo III y comienzos del siglo IV, existen breves y ambiguas referencias en torno a la presencia de piratas bárbaros de origen franco en las costas hispanas. Véase: Haywood 1991, 40, nota 10; De Souza 2002, 228; Álvarez Jiménez 2010, 159-168 y 512. Tampoco podemos afirmar que no existieran grupos endógenos que se dedicaran, ocasionalmente o no, a la piratería (Álvarez Jiménez 2010, 437).

17 Comm. 2.165-188.
}

\footnotetext{
18 Epist. 123.

19 Zos. 6.5.3.

20 Haywood 1991, 88; Wallace-Hadrill 1993, 28-29; Sanz Serrano 2009, 144, entre otros. Álvarez Jiménez no cree factible que la elección del asentamiento visigodo siguiera el objetivo de defender el territorio contra piratas, «aunque no es óbice para descartar que hubieran cumplido con este cometido» (2010, 603).

21 Isid. Hist. Goth. 22; Hyd. Chron. 69.
} 
imperio conllevaron a la retirada de gran parte de las tropas del noroeste galo, debilitando gravemente el limes marítimo hasta su completa desaparición en un momento indeterminado dentro de los siguientes veinte años ${ }^{22}$.

Hacia el 469, el obispo de Chaves Hidacio recoge en su crónica que en el 455 llegaron a la costa lucense - Lucensi litore - siete naves con cuatrocientos hérulos - Erulorum - armados a la ligera, siendo su ataque frustrado por la muchedumbre local que se reunió para hacerles frente, matando a dos de los invasores y obligándoles a huir. Sin embargo, de regreso a sus bases estos hérulos depredaron con saña — crudelissime depraedati - las costas de Cantabria y Vardulia —Cantabriarum et Vardulliarum loca maritima - ${ }^{23}$. La arqueología, con todos los problemas interpretativos que conlleva para el tema que analizamos (De Souza 2002, 227; Álvarez Jiménez 2005, 122), no muestra claros signos de destrucción violenta en los yacimientos costeros en este periodo ni en épocas posteriores. El obispo relata que cuatro años más tarde, de nuevo, unos piratas hérulos depredaron de manera cruel — crudelissime invadunt - el litoral lucense en su camino hacia la Bética ${ }^{24}$. Sidonio Apolinar, obispo de Clermont y, al igual que Hidacio, contemporáneo a los hechos, hacia el $469 / 470^{25}$, en una carta dirigida a su amigo Namatius que residía en Saintes (Charente-Maritime), le hace saber que está al tanto de que había mandado movilizar la flota para perseguir y dar caza a unos piratas sajones. A continuación, Sidonio subraya la fiereza y pericia de los sajones como marineros y señala como muestra de su barbarie la costumbre que tenían de, antes de volver a la mar, ofrecer en sacrificio a uno de cada diez prisioneros, ahogándolo o crucificándolo. De este modo, el obispo recalca que entre estos bárbaros el tormentum de los captivi albergaba cierta prioridad sobre la costumbre de pedir un rescate por su liberación ${ }^{26}$.

La única referencia cronológica que nos ofrece la hagiografía de Severo es el gobierno del emperador Juliano el Apóstata (360-363), época aproximada en la que, según el autor de la obra, el santo gobernaba como rey de unos escitas en un lugar llamado Ambligonia poco antes de renunciar a los títulos y posesiones que ostentaba para dedicar su vida a la religión. De poco nos sirve este dato, ya que la elección de unos orígenes míticos, junto con la fecha de conversión del futuro mártir en unos ańos no exentos de dificultades debido a la política religiosa de Juliano, con la fuerte carga simbólica entre la comunidad cristiana que ello conlleva, persiguen crear una atmósfera emocional adecuada subrayando el incontestable espíritu de sacrificio de Severo. En cuanto al mo-

22 Para aplastar la revuelta bagauda del 435-437 tuvo que acudir un ejército comitatense junto con auxiliares hunos y alanos (Sid. Apol. Carm. 7.246-247; Chron. Gall. Ad. 452, 119; Const. Vit. Germ. 6.28), hecho que revela que las mermadas tropas del tractus, de haber existido todavía, no eran suficientes para derrotar a los bagaudas (Álvarez Jiménez 2010, 471-474 y 605).

23 Hyd. Chron. 164.

${ }^{24}$ Hyd. Chron. 189.

25 Loyen 1934; Larrañaga 2007, 220; Lot 1915, 15; Álvarez Jiménez 2010, 634.

26 Epist. 8.7.13-15. Los vaivenes de los piratas sajones en la zona quedan ratificados por la Vita de Viviano de Saintes, un texto hagiográfico escrito en la primera mitad del siglo vi, que relata la vida del religioso que vivió a mediados del siglo anterior. En dicha vita se recoge que unos bárbaros sajones con muchas naves -multitudo hostium Saxonum barbarorum cum plurimis navibus - atacaron Marciacus (Marsas, Gironde) en tiempos del rey visigodo Teodorico, sin que concrete si se trataba de Teodorico I (419-451) o Teodorico II (453-461). Según el hagiógrafo, los sajones fueron rechazados gracias a un milagro propiciado por las oraciones del santo y que consistió en la llegada de un ejército celestial - militia caelestis - en auxilio de la ciudad (Vit. Viv. 7). No obstante, Courcelle advierte que el pasaje puede corresponder a una reconstrucción elaborada a partir de la información ofrecida por Sidonio. Además, señala que Gregorio de Tours utiliza este relato cambiando el nombre de Viviano de Saintes por el de Similinus de Nantes contribuyendo a ligeras alteraciones en el episodio del ataque pirata (1947, 174-176). 
mento aproximado del ataque vándalo ${ }^{27}$, no existe constancia escrita de la presencia de piratas en el Cantábrico durante la segunda mitad del siglo IV y las fuentes se mantienen mudas al respecto por lo menos hasta la caída del limes, tal como lo hemos citado más arriba. De esta forma, podríamos establecer en el 407-410 la fecha post quem del supuesto asalto pirata que acabó con la vida de Severo. Según la Notitia Dignitatum, un documento oficial redactado a finales del siglo Iv y que recoge el dispositivo militar y la distribución de las tropas del Imperio Romano de Oriente y de Occidente, en la provincia de Novempopulania contamos con una cohorte establecida en Lapurdo (Baiona, Pays Basque) al mando de un tribuno - Tribunus cohortis Novempopulanae-28. El documento no señala que hubiera tropas acantonadas en Palaestrion, pero tampoco dice nada de aquellos enclaves militares bajonavarros de Imus Pyrenaeus (Donazaharre) y Gazteluzahar (Landibarre y Larzabale) ocupados posiblemente durante el Imperio Tardío (Larrañaga 2007, 169). Sin embargo, parece que los barcos vándalos no encontraron resistencia en Lapurdo cuando comenzaron a remontar el Adour. En la actualidad, nadie duda de que la Notitia sufrió cambios y fue actualizada en parte durante las siguientes décadas a su composición, llegando a reflejar una realidad que a comienzos del siglo v solo existía sobre el papel (Neira 2006, 43). Para el caso de Hispania y el Pirineo Occidental ha quedado demostrado que en el 408 no había fuerzas militares profesionales que pudiesen defender el territorio de las usurpaciones ni de las migraciones bárbaras, dejando en evidencia que la información que recoge la Notitia en el momento de su última redacción estaba en cierta medida desfasada ${ }^{29}$.

El hecho de que el autor explicite que los invasores llegaron remontando el río descarta la identificación del ataque como parte de las razias terrestres efectuadas durante dos años por vándalos, suevos y alanos en el sur galo antes de trasladarse en el 409 a la península ibérica ${ }^{30}$. Aunque es posible que el hagiógrafo reconstruyera el pasaje en base a estos acontecimientos ${ }^{31}$. En caso de que creyésemos al anónimo autor cuando identifica a los incursores marítimos con los vándalos, tendríamos que retrasar el ataque al menos hasta las siguientes décadas, ya que esta comunidad germana no comenzó a familiarizarse con el arte de la navegación y a realizar expediciones piráticas hasta su breve estancia hacia el 420 en el sur de Hispania ${ }^{32}$. Las fuentes señalan que los primeros actos de piratería de los Vandali se limitaron en un principio a la vertiente mediterránea de la Península Ibérica y al archipiélago balear (Álvarez Jiménez 2016, 67 y 71), por lo que es inverosímil que en esta fase inicial de aprendizaje llegaran hasta el Cantábrico. En el 429 pasaron a África y diez años

27 El santoral señala el 1 de noviembre como fecha del martirio de Severo, pero es arriesgado suponer que lo fuera así, ya que en la Antigüedad la temporada de navegación terminaba (mare clausum) a comienzos de noviembre, según Plinio el Mayor y Vegecio el 11 de noviembre, y no se volvía abrir hasta febrero-marzo (Plin. Nat. 3.122; Veget. Inst. Milit. 4.39).

28 Not. Dig. Occ. 42.19.

29 En el caso de que el ejército hispano sobreviviera al siglo Iv, el grueso de lo que quedaba de sus tropas habría sido retirado hacia el 401 por Estilicón para defender Italia (Arce 2005, 197-203). Las «legiones de Lusitania» lideradas por los hermanos Dídimo y Veriniano, que menciona Zósimo (6.4.1-4), serían tropas compuestas por gentes y esclavos de sus posesiones peninsulares y los restos de las cohortes hispanas junto con milicias urbanas, burgarii lusitanos (Escribano 2000, 523; Díaz Martínez \& Menéndez Bueyes 2005, 285).

30 Sobre estos hechos: Courtois 1955, 50; Torres Rodríguez 1977, 37; Arce 2005, 55; Larrañaga 2007, 203; Díaz Martínez 2011, 52; Delaplace $2015,136$.

31 Gregorio de Tours recoge una tradición hagiográfica donde se señala que a comienzos del siglo la civitas Vasatica (actual Bazas, Gironde) y su región fueron hostigadas por un rex llamado Gausericus, monarca mencionado únicamente por esta fuente, al mando de unos barbari (Greg. Tur. Glor. Mart. 12), quizá identificables con el rey Gunderico y sus vándalos.

32 En la década de 420 los vándalos asdingos agruparon a los restos de los silingos y de los alanos trasladándose a la Bética (Álvarez Jiménez 2016, 59). 
más tarde se apoderaron de la ciudad de Cartago creando una temible flota de guerra con las embarcaciones que se encontraban amarradas en el puerto cartaginense, comenzando una intensa actividad pirática en el Mediterráneo occidental que se alargó durante casi un siglo. Su radio de acción estuvo limitado a estas aguas, pero existe una excepción que nos lleva hasta el año 445, momento en que Hidacio apunta en su crónica una incursión marítima de los vándalos en Gallaecia. En el contexto de una paz firmada con Roma tres ańos antes y que duró hasta la muerte del emperador Valentiniano III en el 455, el obispo señala que unos Vandali llegaron con sus naves — navibusa Gallaecia capturando muchas familiae de Turonium ${ }^{33}$, en aquel entonces perteneciente al reino suevo.

Hay quien ha sugerido que los vándalos mencionados por Hidacio podrían ser grupos residuales que no pasaron a África o que en realidad eran hérulos o sajones (Courtois 1955, 158; Tranoy 1974, vol. 2, 83; Haywood 1991, 60; Arce 2005, 173), aunque, según se desprende en su crónica, el obispo galaico sabía distinguirlos de otros pueblos (De Souza 2002, 233; Álvarez Jiménez 2016, 133). Aquellos que han analizado dicho pasaje coinciden en que el cronista no nos cuenta todo lo que sabía al respecto y han surgido varias hipótesis que explican la citada incursión. Algunos opinan que la creciente hegemonía sueva sobre la Bética y la conquista de Sevilla pudiera haber causado cierto recelo entre los vándalos estimando oportuno lanzar una operación de corso y bandidaje contra el reino galaico (Clover 1966, 104; Torres Rodríguez 1977, 90; Gillett 2003, 68; López Sánchez 2015, 185-186). Otros creen que quizá la flota vándala actuase al servicio de Roma en las campañas imperiales contra suevos y bagaudas en el norte hispano ${ }^{34}$, o que los vándalos aprovecharon para atacar las costas de sus enemigos suevos durante un viaje comercial o una misión diplomática dirigida a la corte visigoda de Toulouse (Pampliega 1998, 310; Thompson 2002, 180 y 210; Álvarez Jiménez 2016, 133). Esta última hipótesis pierde fuerza si nos percatamos de que en esta época visigodos y vándalos se encontraban profundamente enemistados, ya que hacia el 443 una hija del rey visigodo Teodorico, casada con el príncipe vándalo Hunerico, fue repudiada y devuelta a Toulouse con la nariz y las orejas cortadas bajo el pretexto de participar en una conjura contra su marido. Con este salvaje acto los vándalos buscaban acercar posturas con el emperador Valentiniano III, con quien habían firmado la citada paz en el 442 y acordado el enlace matrimonial entre Hunerico y Eudocia, hija del emperador que por aquel entonces era una nińa de cinco años $^{35}$. Goulard, uno de los pocos investigadores que han analizado la hagiografía de san Severo, explica, aunque de manera fantasiosa y sin profundizar demasiado, que el ataque vándalo de $\mathrm{Pa}$ laestrion sería una acción preventiva ante los preparativos de una posible expedición goda que buscara vengar la afrenta señalada (Goulard 1998, 293-296).

A nuestro parecer, los atacantes vándalos que remontaron el Adour, de haber existido, tuvieron que ser los mismos que menciona Hidacio. De esta forma, en el contexto de la paz vandalorromana acordada en el 442, los territorios pertenecientes al imperio quedarían exentos de ser atacados y los vándalos, en su afán por conservar su potencial marítimo mediante la actividad pirática, habrían

33 Wandali navibus Turonio in litore Gallaeciae repente advecti, familias capiunt plurimorum (Hyd. Chron. 131). Se piensa que Turonium ha de localizarse en algún lugar de la provincia de Pontevedra, en las localidades de Torroña o Tourón (Álvarez Jiménez 2016, 133) o en Santa Elena de Torońa, en Tuy (Torres Rodríguez 1977, 91, nota 154; Sanz Serrano 2009, 483).
34 Merrils \& Miles 2010, 113-114. De ser así constituiría una excepción, pues en los trece años que duró la paz no existe constancia de que el reino vándalo prestase ayuda militar a Roma, ni siquiera en el 451 en la Batalla de los Campos Cataláunicos (Álvarez Jiménez 2016, 134).

35 Jord. Get. 36.184. En torno a estos acontecimientos: Conant 2012, 24-25. 
optado por buscar otros objetivos militares sin ánimo de atentar contra los intereses del emperador Valentiniano. Asimismo, es posible que la expedición del 445 hubiese sido instigada por el propio emperador o se hubiera realizado con el conocimiento de este (Halsall 2012, 266). La captura de varias familiae galaicas durante el ataque, como hemos mencionado más arriba, respondería a una práctica habitual que buscaba el lucro económico mediante su venta como esclavos o su liberación a cambio de un rescate (Torres Rodríguez 1977, 90), aunque en este caso pudiera responder a la propia logística de la expedición. De esta manera, estos captivi, puede que miembros de familias pudientes, podrían haber sido utilizados como rehenes para evitar que los vándalos fueran perseguidos por los suevos, garantizando así el éxito de su cometido y un viaje de regreso seguro (Gillett 2003,56 , nota 70). Suponemos que las costas várdulas y vasconas habrían sido respetadas por su pertenencia a la provincia tarraconense, en estos momentos bajo la órbita del emperador.

Debemos ańadir que la intervención milagrosa de un religioso en contra de grupos piratas que hostigaban a una comunidad católica durante el periodo tardoantiguo es un recurso utilizado por varios hagiógrafos de época medieval. La Vita de Marculphus, una obra redactada con anterioridad al siglo $\mathrm{x}$, recoge la biografía de un santo que vivió en la primera mitad del siglo vi. En una ocasión, la labor evangelizadora llevó a Marculfo hasta Jersey, isla habitada por unas pocas decenas de personas dedicadas a la ganadería. Mientras el religioso se encontraba en el lugar, sus habitantes le pidieron ayuda ante la llegada de 3000 sajones dispuestos a atacar el territorio, ofensiva que se vio frustrada gracias a los rezos del santo que ocasionaron una terrible tormenta que destruyó la flota invasora. Tras fundar un monasterio, Marculfo se marchó del lugar ${ }^{36}$. La apócrifa obra De s. Helerio vel Elerio mart. In Caesarea Maris Britannici insula, un texto redactado hacia los siglos X-XI y posterior a la Vita de Marculfo - pues utiliza una de sus versiones como fuente- señala que los habitantes de Jersey pudieron escapar de unos piratas provenientes de las Orcadas - Orcadumgracias a que fueron avisados por el religioso Helerio que en esos momentos se hallaba en la isla. En cambio, algunos años después (hacia el 555) el religioso fue apresado en el mismo lugar por unos incursores vándalos - Wandali-y decapitado. Al igual que Severo de Novempopulania, Helerio también fue cefalóforo, es decir, después de muerto caminó con la cabeza entre sus manos, solo que en este caso el prodigio sirvió para que los piratas huyeran aterrorizados ${ }^{37}$. Si nos remitimos a los hechos que pudieran calificarse de históricos, la presencia de unos piratas vándalos a mediados del siglo vi navegando por el Canal de la Mancha resulta inaceptable, más cuando su reino norteafricano fue conquistado por los bizantinos y sus habitantes deportados a Oriente en el 535. La identificación de estos piratae como Wandali puede responder a que su fiereza y peligrosidad como piratas quedara grabado en el imaginario colectivo, ya que dicho pueblo fue uno de los que más destacó por sus incursiones marítimas durante el siglo v (Âlvarez Jiménez 2005, 117). Por ello, no contradecimos las afirmaciones que señalan la nula credibilidad de estas fuentes apócrifas, aunque, al igual que el doctor Álvarez Jiménez, somos de la opinión de que pudieran guardar un fondo real vinculado, en este caso, a la amenaza pirática a la que estaban sometidas las comunidades costeras durante esta época (Álvarez Jiménez 2010, 638).

En cuanto al proceder pirata, generalmente desconocemos cuál sería la media de naves y de hombres que participarían en cada acción pirática en la Antigüedad Tardía. De entre todas las referencias literarias conservadas, el único dato fiable es el ofrecido por Hidacio cuando señala que los hérulos llegados en el 455 a Gallaecia lo hicieron con siete naves y 400 hombres. Como hemos visto, el obispo de Chaves indica que los piratas encontraron una resistencia organizada en la costa 
lucense y que decidieron volverse a la mar tras perder a dos de sus hombres. Podemos aceptar el número de barcos y tripulantes que se recoge en la crónica hidaciana como la cifra media de una partida saqueadora, ya que incluye cierto potencial de asalto lo bastante contenido como para poder evitar ser detectados con la suficiente antelación, a la vez que adecuado para realizar acciones inesperadas y de retirada (Álvarez Jiménez 2010, 610). De esta forma, conscientes de su modesto potencial bélico frente a un oponente organizado, los praedes evitaban asumir riesgos y se retiraban una vez perdían el factor sorpresa (Álvarez Jiménez 2005, 121). Así, el éxito de su ataque dependía de la imprevisibilidad de la misma y de la brutalidad empleada, tal como lo comenta Sidonio Apolinar cuando habla sobre los archipiratae sajones. Los vándalos que, siguiendo al texto apócrifo, mataron a Severo, no optaron por retirarse, quizá por lo inesperado de su incursión y por su superioridad numérica respecto al destacamento de Palaestrion, ventaja que mantuvieron a pesar de perder parte de sus fuerzas debido, según la tradición, a la inundación desatada por los rezos del religioso.

En cuanto a las defensas antipiráticas presentes en el Cantábrico, mientras el reino suevo carecía de ellas —al menos de manera oficial—, hemos podido comprobar que los visigodos disponían de una fuerza naval en el estuario del Garona al mando de un tal Namatius. Muchos opinan que se trataría de una flota de origen romano que existiría con anterioridad al asentamiento visigodo en Aquitani ${ }^{38}$. La verdad es que no sabemos si era así o si se trataba de una flota creada para la ocasión, y tampoco conocemos su tamańo. Sidonio apremia a su amigo Namacio para que le escriba y le mantenga informado, pero este no lo hizo o su respuesta no se ha conservado. Por ello, desconocemos la duración de la campaña, dónde transcurrió y si esta tuvo éxito (Álvarez Jiménez 2010, 634). Finalmente, cabe pensar que el enclave de Palaestrion formaría parte del sistema defensivo del reino visigodo de Toulouse, una guarnición que junto con otras acuarteladas en las civitates más importantes y otros castra formaría una red a lo largo del río Adour que, junto con Lapurdo, Atura (Aire-sur-l'Adour, Landas) y Turba (Tarbes, Altos Pirineos) controlara el territorio frente a los ataques externos y sirviese para consolidar la autoridad visigoda sobre la recién anexionada provincia romana de la Novempopulania ${ }^{39}$. De esta manera, observamos que el reino visigodo se valía de las fuerzas tanto navales como terrestres para contrarrestar y repeler los ataques de piratas, logística heredada de las infraestructuras antipiráticas del Imperio Romano.

\section{Conclusiones}

A pesar de la lógica preferencia de los historiadores por utilizar fuentes de carácter fiable y contemporáneo a la hora de reconstruir los hechos históricos, ante la parquedad o ausencia de estas cabe poner el acento en otro tipo de obras, aunque su veracidad resulte dudosa por su carácter apócrifo y redacción tardía. En el caso de la piratería en el Cantábrico durante la Tardoantigüedad, defendemos la utilidad de la hagiografía medieval de Severo de Novempopulania, siempre y cuando tengamos en cuenta que sus posibles aportaciones a nuestro estudio han de tratarse con suma cau-

38 Lot 1915, 15, nota 1; Haywood 1991, 59, nota 58; De Souza 2002, 231, nota 23.

39 Goulard 1996, 162. Según Rouche, los visigodos habrían anexionado la Novempopulania hacia el 436 y dicha ocupación habría sido reconocida por Roma tras la debacle de las tropas romanas comandadas por Litorio en el 439 en la batalla de Toulouse (1979, 31-32). Goulard opina que la sede regia de los visigodos en la Novempopulania se ubicaría en la civitas de Atura (1996, 161). 
tela debido a la naturaleza apócrifa del texto y a que fuera redactado casi seis siglos después de los hechos que recoge.

Hemos señalado que, a la hora de escribir el pasaje en torno al ataque pirata, es posible que el autor realizara una reconstrucción de los hechos cuyo trasfondo nos retrotraería a la breve estancia que realizaron los vándalos en el suroeste galo antes de atravesar los Pirineos en el 409. No obstante, en su redacción, creemos más factible la influencia de una base real relacionada con la amenaza pirática latente durante el siglo $\mathrm{v}$, sea verdadero o no que unos vándalos llegaran hasta el Cantábrico oriental. Los testimonios que nos han llegado sobre los acontecimientos piráticos en el Golfo de Bizkaia resultan insuficientes, pero son lo bastante representativos como para comprender que los ataques piratas no eran tan excepcionales como se piensa. Asimismo, la incursión vándala del 445 en Gallaecia, señalada como excepcional por su alejamiento geográfico y por el contexto en el que se efectúa - la paz vandalorromana (442-455) - por aquellos investigadores que la consideran verídica, pudiera formar parte de una expedición saqueadora más ambiciosa que pretendiese buscar nuevos objetivos militares, llegando a atacar las costas novempopulanas, en estos momentos pertenecientes al reino visigodo de Toulouse. El itinerario utilizado en la ida y en la vuelta, largo y peligroso, requeriría tomar ciertas precauciones, como la captura de algunas familias de Gallaecia que sirvieran, quizá, como rehenes, evitando de esta manera que las autoridades suevas reaccionaran y pusiesen en peligro el éxito de la misión.

\section{BibLIOGRAFÍA}

Allen, J., 2006, Hostages and hostage-taking in the Roman Empire, Cambridge: Cambridge University Press. ÁlvareZ JimÉneZ, D., 2005, «Instrumentos para el estudio de la piratería tardoantigua», en: F. Echeverría, M. Y. Montes (eds.), Actas del IV Encuentro de Jóvenes Investigadores de Historia Antigua. Metodología en Historia Antigua. Problemas de interpretación, Cersa, 113-128.

Álvarez Jiménez, D., 2010, La piratería en la Antigüedad Tardía, Tesis doctoral, Universidad Complutense de Madrid.

Álvarez JimÉneZ, D., 2016, El reino pirata de los vándalos, Sevilla: Universidad de Sevilla.

Álvarez Pérez-Sostoa, D., 2009, Los rehenes en la República Romana: función social, política e ideológica (264-31), Tesis Doctoral, Universidad del País Vasco-Euskal Herriko Unibertsitatea.

ArCE, J., 2005, Bárbaros y romanos en Hispania. 400-507, Madrid: Marcial Pons.

ARCE, J., 2009, El último siglo de la España Romana, 284-409, Madrid: Alianza.

Baillet, C., 2009, "Une lectura du dossier hagiographique de saint Sever, martyr en Gascogne», en: B. Cursente, J. Cabanot (eds.), Abbaye de Saint-Sever. Nouvelles approches documentaires (988-1359). Journées d'études Saint Sever, 13-14 septembre 2008, Dax: Société de Borda, Sciences, Lettres et Arts des Landes Comité d'Études sur l'Histoire et l'Art de la Gascogne, 55-93.

Bielman, A., \& P. Duckrey, 2003, «Sort partagé, sort allégé? Confrontation entre destins collectifs et destins individuels de prisonniers dans le monde antique», en: S. Caucanas, R. Cazals, P. Payen (dir.), Les prisonniers de guerre dans l'hitoire. Contacts entre peuples et culture, Toulouse: Les Audois, 75-94.

Braund, D., 1993, «Piracy under the principate and the ideology of imperial eradication», en: G. Shipley, S. Graham (ed.), War and society in the Roman world, London and New York: Routledge, 195-212.

Саваnot, J., \& G. Pon, 2009, «Les origines. La légende et la fondation», en: B. Cursente, J. Cabanot (eds.), Abbaye de Saint-Sever. Nouvelles approches documentaires (988-1359). Journées d'études Saint Sever, 13-14 septembre 2008, Dax: Société de Borda, Sciences, Lettres et Arts des Landes Comité d'Études sur l'Histoire et l'Art de la Gascogne, 31-54.

Clover, F. M., 1966, Genseric the statesman: a study of Vandal foreign policy, Chicago: UMI Dissertation Services. 
Conant, J., 2012, Staying Roman. Conquest and identity in Africa and the Mediterranean, 439-700, Cambridge: Cambridge University Press.

Connolly, S., 2006, «Roman ransomers», $A H B$ 20, 1-4, 115-131.

Courcelle, P., 1947, "Trois dîners chez le roi wisigoth d'Aquitaine», Revue des études anciennes, 49, 169177.

Courtois, C., 1955, Les Vandales et l'Afrique, Paris.

De Souza, P., 2002, Piracy in the Graeco-Roman World, Cambridge: Cambridge University Press.

Delaplace, C., 2015, La fin de l'Empire romain d'Occident. Rome et les Wisigoths de 382 à 531, Rennes: Presses Universitaires de Rennes.

Díaz Martínez, P. C., 2011, El reino suevo (411-585), Madrid: Akal.

Díaz Martínez, P. C., \& C. R. Menéndez Bueyes, 2005, "The Cantabrian basin in the fourth and fifth centuries», en: K. Bowes, M. Kulikowski (eds.), Hispania in Late Antiquity. Currents perspectives, LeidenBoston: Brill, 265-297.

Duckrey, P., 1968 [rééd. 1999], Le traitement des prisonniers de guerre dans la Grèce antique des origines à la conquête romaine, Paris.

Escribano, M. V., 2000, «Usurpación y defensa de las Hispanias: Dídimo y Veriniano (408)», Gerión 18, 509-534.

Goulard, R., 1996, «Les goths parmi les neuf peuples au ve siècle», Lapurdum 1, 157-169.

Goulard, R., 1998, «La bataille du Palestrion octobre-novembre 445» Lapurdum 3, 293-297.

Gueye, M., 2013, Captifs et captivité dans le monde romain. Discours littéraire et iconographique (III siècle av. J.-C.-II siècle ap. J.-C.), Paris: L'Harmattan.

Guillett, A., 2003, Envoys and Political Communication in the Late Antique West, 411-533, Cambridge: Cambridge University Press.

Halsall, G., 2012, Las migraciones bárbaras y el occidente romano, 376-568, Valencia: Universitat de Valencia.

Haywood, J., 1991, Dark age naval power. A re-assessment of Frankish and Anglo-Saxon seafaring activity, London-New York: Routledge.

Herrman-Otto, E., 2002, «Modes d'acquisition des esclaves dans l'Empire roman. Aspects juridiques et socio-économiques», en: M. Garrido-Hory (ed.), Routes et marchés d'esclaves, 26e colloque du GIREA, Bibliographie Besançon, 27-29 septembre 2001, Paris: Presses Universitaires de Franche-Comté, 113-126.

Huntzinger, H., 2009, La captivité de guerre en occident dans l'Antiquité tardive (378-507), Thèse de doctorat, Université de Strasbourg.

Lanz, J., 2015, "En torno a una posible deditio en el Eucharisticos de Paulino de Pella», en: N. Olaya, C. Montoza, A. Aguilera, R. Gómez (eds.), II Jornadas Predoctorales en Estudios de la Antigüedad y de la

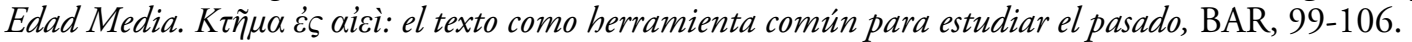

Lanz, J., 2016, "A propósito de una legatio en el "Ara de Hasparren»", en: R. Cordeiro Macenlle, A. Vázquez Martínez (ed.), Estudos de Arqueoloxia, Prehistoria e Historia Antiga: achega dos novos investigadores, Santiago de Compostela: Andavira, 537-552.

Lanz, J., 2017, Dinámicas de enfrentamiento, colaboración y resolución de conflictos en el entorno circumpirenaico occidental (siglos II a.C.-VIII d.C.), Tesis doctoral, Vitoria-Gasteiz.

LARRAÑAga, K., 2007, El hecho colonial romano en el área circumpirenaica occidental, Vitoria-Gasteiz: UPV/ EHU.

Lee, A. D., 2007, War in Late Antiquity: A Social History, Oxford: Oxford University Press.

Lenski, N., 2011a, "Captivity and romano-barbarian interchange», en: R. W. Mathisen, D. Shanzer (eds.), Romans, barbarians and the transformation of the roman world. Cultural interaction and the creation of identity in Late Antiquity, Ashgate: Routledge, 185-198.

Lenski, N., 2011b, «Captivity and Slavery among the Saracens in Late Antiquity (ca. 250-630 CE)», AnTard. 19, 237-266.

Lenski, N., 2014, "Captivity among the barbarians and its impact on the fate of the Roman Empire», en: M. Maas (ed.), The Cambridge companion to the Age of Attila, Cambridge: Cambridge University Press, 230-246. 
Lindenlauf, A., 2003, «The sea as place of no return in Ancient Greece», World Archaeology 35.3, 416433.

López Sánchez, F., 2015, «The Suevic kingdom. Why Gallaecia?», en: J. D’Emilio (ed.), Culture and society in Medieval Galicia. A cultural crossroads of the edge of Europe, Leiden: Brill, 176-209.

Lot, F., 1915, «Les migrations saxonnes en Gaule et en Grande-Bretagne du III $^{\mathrm{e}}$ au v viècle», Revue Historique 119.1, 1-40.

Loyen, M. A., 1934, "Les débuts du royaume wisigoth de Toulouse», Revue des études latines, t.12, 406415.

Merrils, A., \& R. Miles, 2010, The vandals, Chichester: Wiley-Blackwell.

NeIra, C. (ed.), 2005, La Notitia Dignitatum: nueva edición crítica y comentario histórico, Madrid: Consejo Superior de Investigaciones Científicas.

Pampliega, J., 1998, Los germanos en España, Barañain: EUNSA.

Rampazzo, N., 2005, "Il bellum Iustum e le sue cause», Index 33, 235-261.

Rouche, M., 1979, L'Aquitaine: des Wisigoths aux Arabes, 418-781: naissance d'une région, Paris.

Thompson, E. A., 1977, «Britain, A.D. 406-410», Britannia, 8, 303-318.

Thompson, E. A., 2002, Romans and barbarians: the decline of the Western Empire, Wisconsin: University of Wisconsin Press.

Tranoy, A., 1974, Hydace, Chronique, 2. vol. intr. texte critique, traduction, Paris: Les ed. du Cerf.

Torres Rodríguez, C., 1977, El reino de los suevos [Galicia sueva], La Coruña: Fundación Barrie de la Maza.

Sanz Serrano, R., 2009, Historia de los Godos. Una Epopeya histórica de Escandinavia a Toledo, Madrid: La esfera de los libros.

SHAw, B., 1984, «Bandits in the roman empire», Past and Present 105, 3-52.

Wallace-Hadrill, J. M., 1993, The long haired kings, Toronto: University of Toronto Press. 